\title{
IoT Sistemlerde Sınır Bilişim Destekli Anomali Tespiti
}

\author{
${\text { Mert Kışlakç1 }{ }^{1 *} \text { ve Mahmut Durgun }}^{2}$ \\ $1^{1^{*}}$ Tokat Gaziosmanpaşa Üniversitesi, Lisansüstü Eğitim Enstitüsü, Mekatronik Mühendisliği ABD., Tokat, Türkiye, (ORCID: 0000-0001-8506-7498), \\ mertkislakci@gmail.com \\ 2 Tokat Gaziosmanpaşa Üniversitesi, Mühendislik Fakültesi, Mekatronik Mühendiliği Bölümü, Tokat, Türkiye (ORCID: 0000-0002-5010-687X), \\ mahmut.durgun@gop.edu.tr
}

(1st International Conference on Applied Engineering and Natural Sciences ICAENS 2021, November 1-3, 2021)

(DOI: 10.31590/ejosat.1006603)

\begin{abstract}
ATIF/REFERENCE: Kışlakçı, M., Durgun, M. (2021). IoT Sistemlerde Sınır Bilişim Destekli Anomali Tespiti. Avrupa Bilim ve Teknoloji Dergisi, (28), 481-488.

Öz

Endüstriyel uygulamalarda artık insan denetimine ihtiyaç duymayan, sürekli çalışırken aynı zamanda da birbirleriyle iletişim kurabilen sistemler üzerine çalışmalar yapılmaktadır. Fakat bu sistemlerde yaşanan beklenmedik arızalar üretim sürecini sekteye uğratmaktadır. Arızaların plansız olması, yedek parça stokunun bulunmaması, parça tedarik süresi gibi durumlar da üretimin devamlılığını engelleyen faktörlerdir. Endüstriyel uygulamalarda bir diğer sorun ise sistemlerin yeterli verimlilikte çalışmaması sebebiyle israf ettiği kaynaklardır. Bunun neticesinde verimli çalışmayan sistem gereksiz kaynak tüketimi yaparken, verimli çalışan ekipmanlar ise bakım periyotları sırasında kullanılabilecek durumda olmasına rağmen yenisi değiştirilerek maliyeti arttırmaktadır. Yine de düzenli yapılan bakımlar sistemin arıza yapmamasına engel olamamaktadır. Bunun nedeni sistemin gerçek zamanlı takip edilememesinden, arızaya ne veya nelerin sebep olduğunun bilinmemesidir. Bu proje kapsamındaki IoTSBDAT (IoT Sistemlerde Sınır Bilişism Destekli Anormallik Tespiti) teknolojisi ile üretim sürecinde yer alan ekipmanlar nesnelerin internetine (IoT) sahip düğüm noktalarına dönüştürülerek her ekipmandan gerçek zamanlı veri alınacaktır. Ekipmandan gelen değerler sınır bilişim adı altında birleştirilerek yapay zekâ vasıtasıyla yerel noktalardaki veriler ile gerçek zamanlı olarak eğitilir. Eğitim sonuçları ve sistemin gerek duyduğu veriler önce burada depolanır, daha sonra sınır katmanında analiz edilen veriler bulut katmanında depolanmak üzere aktarılır. IoTSBDAT çalışması sistemlerin gerçek zamanlı izlenmesini mümkün hale getirirken yapay zekâ sayesinde ekipman kaynaklı arızaların tespitini amaçlamaktadır. Bulut sistemlerinde yaşanan problemlerde veya yerel noktalardaki veri iletiminde herhangi bir kopukluk olması durumunda ise sınır bilişim katmanında veriler saklanır sistem normalde döndüğünde depolanan veriler buluta aktarılarak veri kaybı engellenir. Sistemin gerçek zamanlı izlenmesi neticesinde arızalar önceden kestirilerek gerekli yedek parça tedariki ve bakım aralıkları planlanır, kullanılan kaynaklardan tasarruf edilirken bakım harcamalarındaki maliyetleri düşürmeyi hedeflemektedir.
\end{abstract}

Anahtar Kelimeler: Yapay Zekâ, Nesnelerin İnterneti (IoT), Anormallik Tespiti, Sınır Bilişim, Kestirimci Bakım.

\section{Edge Computing Assisted Anomaly Detection in IoT Systems}

\begin{abstract}
In industrial applications, studies are carried out on systems that no longer need human control and can communicate with each other while working continuously. However, unexpected failures in these systems disrupt the production process. Unplanned failures, insufficient spare parts stock and part supply time are also factors that hinder the continuity of production. Another problem in industrial applications is the resources wasted by the systems due to insufficient efficiency. As a result, the system that does not work efficiently consumes unnecessary resources, while replacing it while efficient equipment is available during maintenance periods increases the cost. However, regular maintenance cannot prevent the system from malfunctioning. This is due to the fact that the system cannot be monitored in real time, it is not known what or what caused the error. Within the scope of this project, with IoTSBDAT (Border Information Assisted Anomaly Detection in IoT Systems) technology, the equipment involved in the production process will be converted into node points with the Internet of Things (IoT) and real-time data will be obtained from each equipment. The values obtained from the equipment are combined under the name of border computing and trained in real time with data from local points through artificial intelligence. The training results and the data needed by the system are stored here first, then the data analyzed at the boundary layer is transferred to be stored in the cloud layer. The IoTSBDAT study makes real-time monitoring of systems possible, while AI aims to detect equipment-induced failures. In the event of problems with cloud systems or any disconnection in data transmission at local points, data is stored in the boundary computing layer, preventing data loss by transferring stored data to the cloud when the system normally returns. As a result of real-time monitoring of the system, failures are foreseen and the necessary spare parts supply and maintenance intervals are planned and maintenance costs are reduced while saving the resources used.
\end{abstract}

Keywords: Artificial Intelligence, Internet of Things (IoT), Anomaly Detection, Edge Computing, Predictive Care. 


\section{Giriş}

Dündar ve ark. yaptıkları çalışma neticesinde endüstriyel ekosistemdeki makine arızalarını önleyerek üretimde oluşabilecek kesintileri azaltarak ilgili maliyetleri düşürmenin etkin bir bakım yönetimi ile mümkün olabileceğini savunmuşlardır[1]. İlave bakım yönetimi önleyici, düzeltici ve kestirimci bakım operasyonlarının yönetilmesi çalışmalarını içermektedir[2]. Sensör ve bilişim sistemlerindeki gelişmelerle kestirimci bakım çalışmaları endüstriyel uygulamalar için son derece önem kazanmıştır[3]. Veri bilimine dayalı makine öğrenimi algoritmalarının katkısıyla güçlendirilen kestirimci bakım sistemleri, yeni üretim sistemlerinin vazgeçilmez bir parçası olarak geliştirilir[4]. Son yıllarda, arızaların gerçek zamanlı tespit edilmesi, sistem durumunun anlık izlenmesi konuları yeni bir eğilim haline gelmiş ve kestirimci bakım alanlarında akademik çalışmalar hız göstermiştir[5]. Kestirimci bakım, sistem içerisinde oluşabilecek arızaları oluşmadan önlemek maksadıyla bakımın hangi anda ne zaman yapılabileceğini tahmin etmeye odaklanır[6]. Arızalar, hatalı ekipmanlar, etkin olmayan zaman dilimleri gibi israfları önlemede etkin bir rol oynamaktadır.

Endüstriyel çaplı Nesnelerin İnterneti (IIoT) bilinen diğer adı ile Endüstri 4.0, ekipman kullanımı, süreç maliyeti, işçi verimliliği konularına daha fazla yoğunlaşılmıştır[7]. Endüstriyel IoT, düşük maliyetli sensörleri etkili bir biçimde operasyona dahil edilmesi ile ilgilidir. Makine verilerini toplamak ve elde edilen veriler ile anlamlı sonuçlar çıkarmak için ileri analitik yapılar kullanılmaktadır.

Endüstriyel IoT'nin üreticilerin verilimliliklerini $\% 30$ artırmalarına izin vereceği tahmin edilmektedir [8].

Karmaşık ortamlarda birden çok kaynaktan veri toplarken gerçek zamanlı sistemler için zorluk teşkil etmektedir[9]. Zamana bağlı birkaç sensörün veri paketleri ilettiği IoT ortamlarında, ilgili maliyetler (örneğin bant genişliği sınırlamaları ve enerji hususları) nedeniyle veri toplama hızı sınırlı olabilir. Ayrıca, veri üretimiyle ilgili ortam karmaşıklığı, veri toplarken kritiklik ve zamanlılığı dengelemek için ek zorluklar getirebilir[10].

Bilişim teknolojileri insan yaşamının her alanını gün geçtikçe değiştirmektedir. Bu bağlamda Edge Computing, Internet of Things, Machine Learning ve Big Data Analytics teknolojilerinin de bu değişimin bir parçası olduğu düşünülüyor. Edge bilişim, uzak bulut ortamlarından bilgi işlem gücünü ağların uç noktalarına/kenarlarına getirmeyi amaçlar. Böylece akıllı uygulamalar tüm verilerini buluta göndermek ve cevapların aynı uzun rota üzerinden geri gelmesini beklemek zorunda kalmiyor[11].

Nesnelerin endüstriyel internetinde IIoT, binlerce parça donanım, alet ve çeşitli denetleyiciler söz konusu olduğundan, temel sorun sensörlerdir. Sensörleri kullanarak algılama, IIoT'nin alt satırıdır ve IIoT sisteminin algılama doğruluğunu ve kontrol göstergelerini doğrudan etkiler. Ancak, IIoT cihazları tarafından üretilen çok sayıda gerçek zamanlı veri bulut bilgi işlem merkezlerine aktarıldığında, büyük ölçekli veriler kaçınılmaz olarak bilgi işlem yükünü getirecek ve bu da bulut bilgi işlem merkezlerinin bilgi işlem hızını etkileyecek ve bulut bilgi işlem veri merkezlerinin bilgi işlem yükünü artıracaktır. Bu faktörler, IIoT'de gerçek zamanlı olarak toplanan sensör verilerinde doğrudan kararsızlığa ve gecikmeye yol açar[12].
Bu çalışmada endüstriyel sistemleri nesnelerin interneti (IoT) ekosistemine dahil ederek veri üretebilen noktalar haline getirmek ve daha sonra elde edilen bu veriler ile çeşitli yapay zekâ modelleri kullanılarak sistemdeki anormalliklerin algılanması amaçlanmıştır.

Proje kapsamında tek fazlı elektrik motorundan gelen değerler gerçek zamanlı verileri toplamak için geliştirilen IoT bir cihaz ile toplanacaktır. Elde edilen bu veriler yerel noktalarda bulunan sınır bilgisayarlarına aktarılarak yapay zekâ modelinin eğitilmesi hedeflenmektedir. Sistem için gerekli olan kıymetli veri bulut ortamına aktarılıp depo edilir. Depo edilen kıymetli veri üzerinde elektrik motorunun zaman dilimlerine göre harcadığ enerji, zaman serilerine bağlı değerleri, gerçekleşen anormallik durumlarının süreleri gibi çeşitli analiz sonuçları çıkarılacaktır. $\mathrm{Bu}$ sayede sistemin her zaman optimum aralıkta çalışması sağlanacaktır.

\section{Materyal ve Metot}

Sistem uygulamalı olarak endüstriyel çalışma ortamında bulanan bir üretim bandına dahil edildi. Periyodik bakımları yapılmasına rağmen elektrik motorunda çeşitli zaman aralıklarında arızalar meydana gelmektedir. Bu sebeple üretim bandından istenilen verim alınamamaktadır. Çalışma kapsamında "IoT Sistemlerde Sınır Bilişim Destekli Anormallik Tespiti" sistemi üretim bandına entegre edilir.

Buna göre arıza tespiti yapılacak ekipmanın nesnelerin interneti (IoT) ekosistemine dahil edilmesi amaciyla üretim bandında bulunan tek fazlı elektrik motoruna ait bir faza akım trafosu bağlanır. Sensörden gelen gerçek zamanlı veriler ağ geçidine (gateway) aktarılır (Şekil-1).

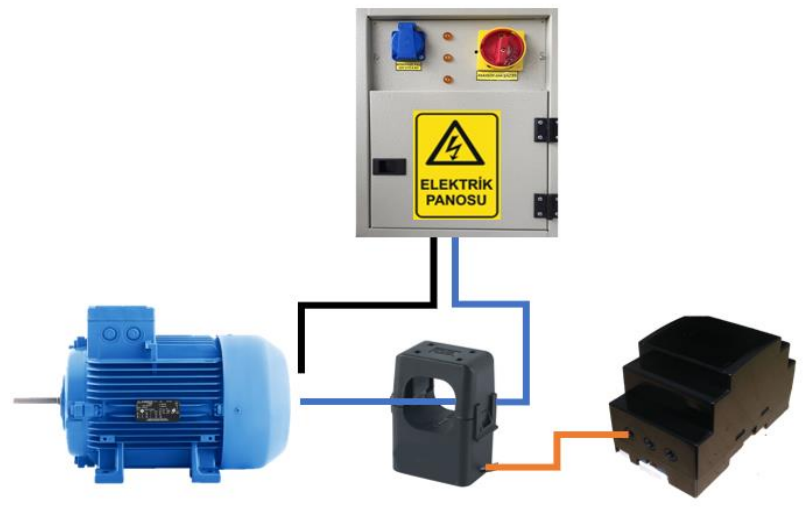

Şekil- 1 Sistem Kurulumu

Ağ geçidinde toplanan veriler yapay zekâ modelinin eğitimi için veri set oluşturmak amaciyla bulut sistemlerine gönderilir. A $\breve{g}$ geçidi çevresel şartlara bağlı olarak bulut katmanına veri iletmek için kablolu (Ethernet) veya kablosuz (Wi-Fi) haberleşme protokollerinden birini kullanabilme yetisine sahiptir. Bulut katmana veri gönderimi esnasından bağlantının kesilmesi durumunda ise ağ geçidinin üzerinde bulunan SD kart aracılığıyla veri kısmi olarak burada saklanır. İletişimin normalde döndüğü esnada ise geçici depolanan veriler bulut katmanına aktarılarak sistemin veri kaybetmesi engellenir. Bulut üzerinde toplanan her veri ekipmanın karakteristik özelliği farklı olabileceğinden; A bandında bulunan motorun özellikleri, yaptığı iş, kullanım süresi $\mathrm{B}$ bandında bulunan motora göre farklılık gösterebilir. Yapay zekâ 
modellerinde genel bir veri setine göre model eğitmek analiz sonuçlarının doğruluğunu düşüreceğinden her ekipmana özel veri seti toplanır ve bu veri setleriyle yine ekipmana özgü yapay zekâ modeli eğitilerek modelin arızayı tahmin etme başarısı yükseltilmektedir. Bulut katmanında bulunan sunucularda ekipmandan gelen veriler belirli periyotlarla yapay zekâ modelleri eğitilir. Eğitim sonucunda ekipmana ait yapay zekâ modelinin ağırlık çıktısı havadan programlama (OTA) ile ağ geçidine aktarılır. Yapay zekâ modeli artık ağ geçidi üzerinde çalıştırılarak motordan gelen anlık akım değerlerinin analiz yapılması sağlanır. $\mathrm{Bu}$ süreçte elde edilen anormal veriler "Kıymetli Veri" adını alarak bulut katmanına aktarılarak analiz sonuçlarının daha sonra incelenmesi maksadıyla saklanır. (Şekil-2)

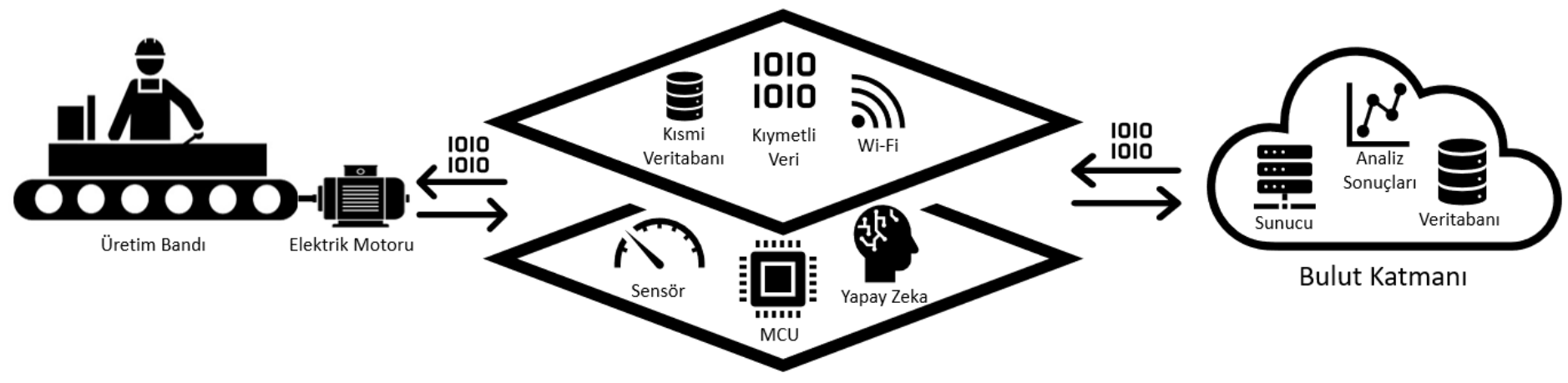

Sınır Bilişim Katmanı

Şekil- 2 Sistem Yapısı

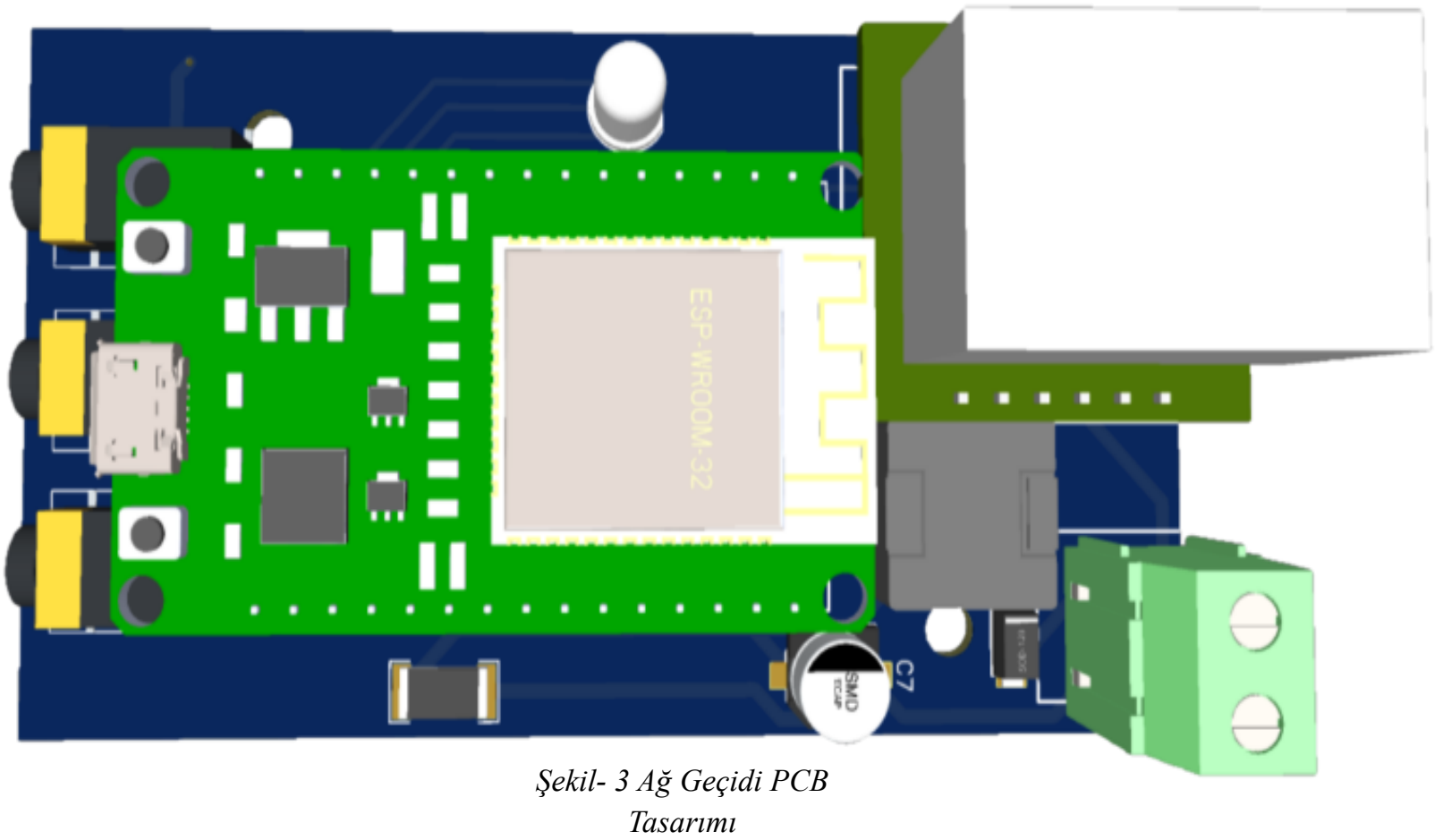




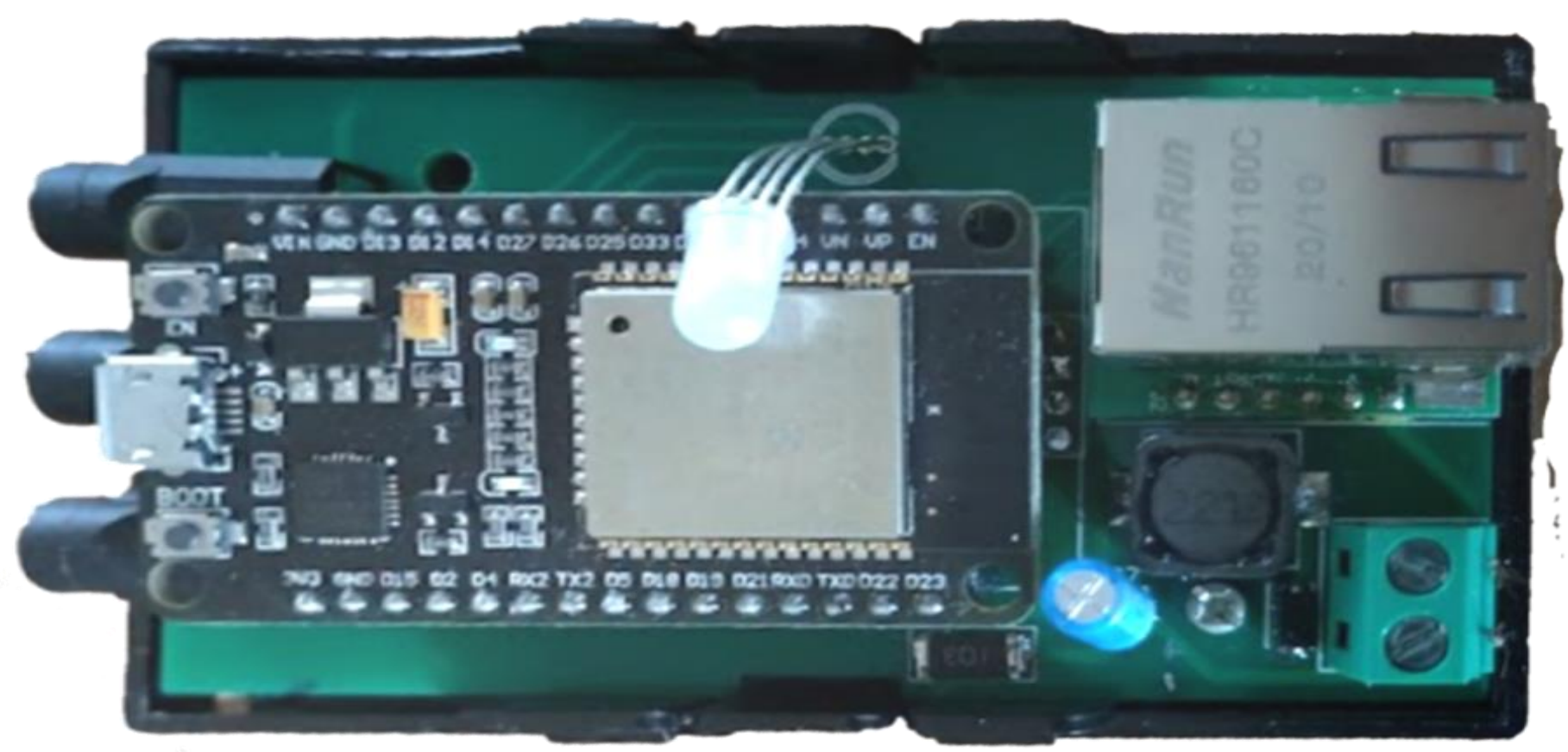

Şekil- 4 Ăg Geçidi

\section{Akım Trafosu}

Akım trafosu devreden geçen akım miktarını ölçmek için kullanılan ölçü bir çeşit transformatördür. Yüksek alternatif akımları ölçü aletleri tarafından direkt olarak ölçülmesi, yüksek maliyetli olmasının yanı sıra bir o kadar da tehlikelidir. İşte bu yüzden devreden geçen akım miktarının ölçülebilmesi için belirli bir referans değerine indirgenmesi gerekmektedir. Devreye seri olarak bağlanabilen akım trafosu, primer devreden geçen akımın meydana getirdiği manyetik alanı indirgeyerek sekonder devreye aktarır. Sekonder devrede oluşan döngüsel akım ile sekonder sargıya paralel bağlanan ölçü aleti primer devreden geçen akım miktarı ölçmektedir [13].

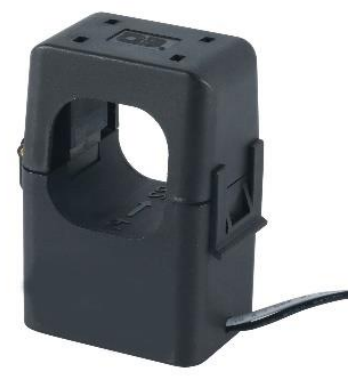

Şekil- 5 Akım Trafosu

\section{ESP32-MCU}

Espressif Systems tarafindan oluşturulan ESP32, çift modlu Bluetooth ve Wi-Fi özelliklerine sahip bir çip ( $\mathrm{SoC}$ ) serisi üzerinde düşük maliyetli, düşük güç tüketen bir sistemdir! ESP32 ailesi, ESP32- D0WDQ6 (ve ESP32- D0WD), ESP32- D2WD, ESP32- S0WD yongalarını içerir., ve paketteki sistem (SiP) ESP32-PICO-D4. Kalbinde, 240 MHz'e kadar saat hızına sahip çift çekirdekli (dual core) veya tek çekirdekli (single core) Tensilica Xtensa LX6 mikroişlemci barındırır. ESP32, gömülü gelen yerleşik anten anahtarları, güç amplifikatörü, RF balun, düşük gürültülü alıcı amplifikatör, filtre türleri ve güç yönetimi modülleri ile yüksek düzeyde entegredir. Mobil ile elektronik cihazlar ve IoT uygulamaları için tasarlanan ESP32, ince çözünürlüklü saat geçişi, çoklu güç modları ve dinamik güç ölçeklendirme gibi güç tasarrufu özellikleri sayesinde ultra düşük güç tüketimi sağlar[14].

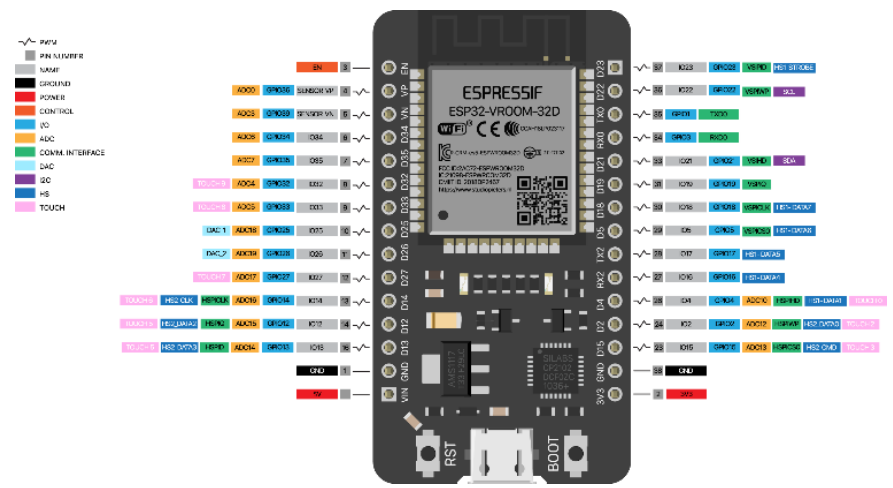

Şekil- 6 ESP32 Pin Çıkışları 
Tablo 1. ESP32 Özellikleri

\begin{tabular}{|c|c|}
\hline ESP32 & TANIM \\
\hline Çekirdek & 2 \\
\hline Mimari & 32 bits \\
\hline Hiz & $\begin{array}{c}\text { Tensilica Xtensa } \\
\text { LX106 160-240MHz }\end{array}$ \\
\hline WiFi & IEEE802.11 b/g/n \\
\hline Bluetooth & Yes- classic \& BLE \\
\hline RAM & 520 KB \\
\hline Flash & Extern QSPI- 16MB \\
\hline GPIO & 22 \\
\hline DAC & 2 \\
\hline ADC & 18 \\
\hline Protokoller & SPI-I2C-UART-I2S- \\
\hline
\end{tabular}

\section{W5500 Lite-Ethernet Modülü}

Ethernet haberleşmesi yapmak için geliştirilmiş bir modüldür. Wiznet'in W5500 entegresi kullanılmıştır. Ethernet haberleşmesi için gereken protokol yazılımları entegre içerisine yüklenmiştir. $\mathrm{Bu}$ sayede karışı ethernet stackleri ile uğraşmadan ethernet haberleşmesi yapabilmenizi sağlar. SPI portu üzerinden (80 Mhz) bağlantı kurulur. Minimal tasarımı sayesinde çok az yer kaplar. Aynı anda 8 bağımsız soketi destekler[15].

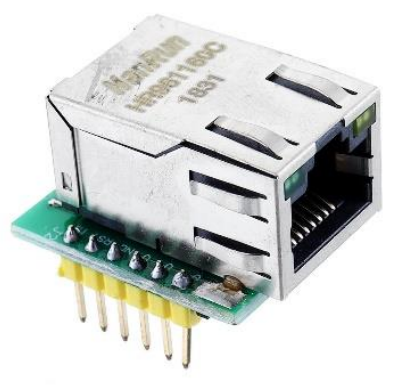

Şekil- 7 Ethernet Modülü

\section{Yapay Zekâ Modeli-LSTM}

Uzun kısa süreli bellek (LSTM), değerleri rastgele aralıklarla hatırlayarak tekrarlayabilen bir sinir ağı (RNN) mimarisidir. Öğretilen ilerleme kaydedildiğinde gizli katmanda saklanan değerler değiştirilemez. RNN'ler, nöronlar arasında ileri ve geri bağlantılara imkân verir. Bir LSTM, önemli durumlar arasındaki bilinmeyen boyutları ve süreleri zaman gecikmeleri göz önüne alınarak zaman serilerini sınıflandırmak, öngörmek ve işlemek için oldukça uygun bir mimaridir. Boşluk uzunluğuna göreceli duyarsızlık, alternatif RNN'ler, gizli Markov modelleri ile sayısız uygulamadaki diğer dizi öğrenme yöntemlerine kıyasla LSTM'ye bir büyük bir avantaj sağlamaktadır[16].

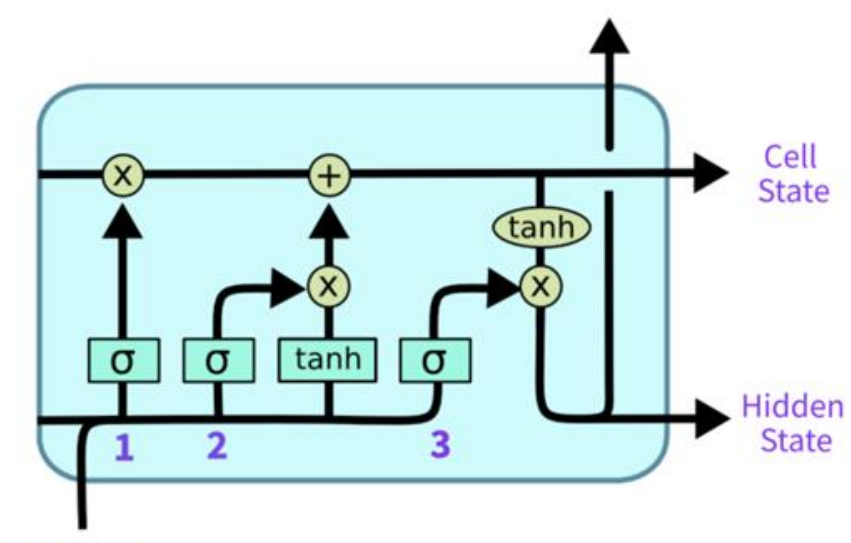

Predictors

Şekil- 8 LSTM Katmanı[17].

\section{Ăg Geçidi (Gateway)}

"IoT Sistemlerde Sınır Bilişim Destekli Anomali Tespiti" sistemi tespit edilecek arızanın türüne göre bünyesinde çeşitli görevlere uygun ağ geçitleri (gateway) barındırmaktadır.

- Dijital ile analog sensörden gelen her türlü veri toplanabilmektedir.

- Çevre şartlarına uygun olarak kablolu (ethernet) veya kablosuz (Wi-Fi) haberleşme protokollerini desteklemektedir.

- $\quad$ A ğ geçidinin üzerinde bulunan güç girişi üzerinden 245 volt aralıklarında doğru akım ile besleme yapilabilmektedir.

- LC yıkıcı ani voltaj artışlarına karşı alçak geçiren (lowpass) filtre devresine sahiptir.

- Bulut katmanı ile iletişimi esnasında sorun olması durumunda geçici veri depolama birimi mevcuttur.

- Havadan güncelleme (OTA) ile eğitimi gerçekleştirilen yapay zekâ modelleri entegre edilebilir.

- Üzerinde bulunan bildirim 1 şı̆̆ı ile ağ geçidinin (gateway) arıza, ikaz ve devreye alındığıyla ilgili geri bildirim vermektedir.

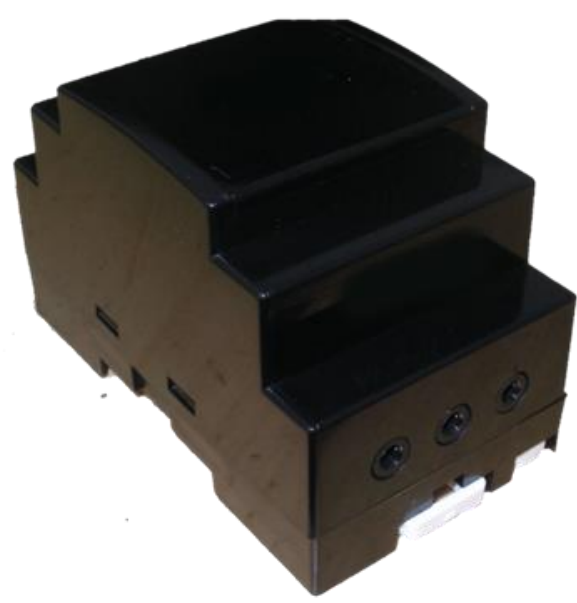

Şekil- 9 Ăg Geçidi (Gateway) 


\section{Bulgular}

Yapılan çalışmanın laboratuvar ortamında bilimsel bulgular çıartılması ve sistemin test edilebilmesi amaciyla tek fazlı elektrik motorunun bir fazına akım trafosu bağlanmıştır (Şekil10).

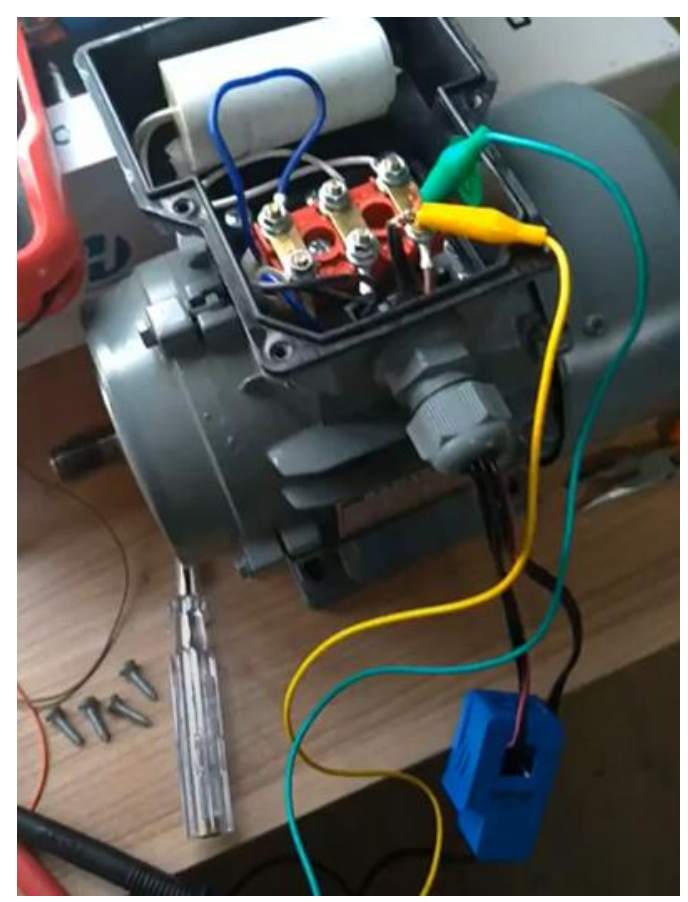

Şekil- 10 Tek Fazlı Elektrik Motoru

Avometre ile yapılan ölçümlerde motorun çektiği akım miktarı 2,7 - 2,9 Amper aralı̆̆ında olduğu tespit edilmiştir (Şekil-11).

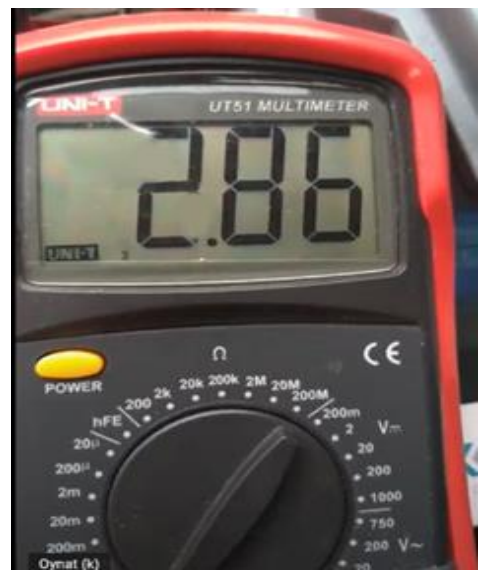

Şekil-11 Motorun Çektiği Akım Miktarı

Sensörden gelen veriler ağ geçidi (gateway) vasıtasıyla kablosuz haberleşme protokolü (Wi-Fi) üzerinden MQTT kullanılarak buluta aktarılmıştır. Akım miktarının ise avometreye kıyasla \% 1,5 hata payı ile ölçtüğü gözlenmiştir (Şekil-12).

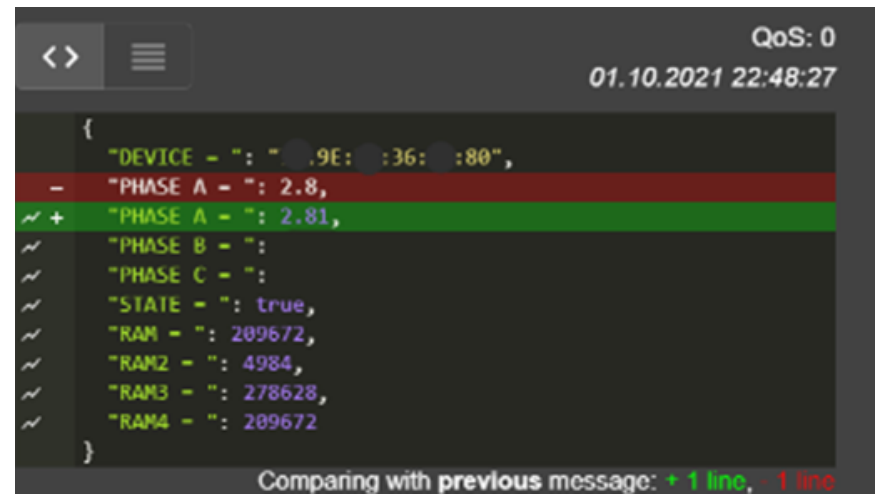

Şekil- 12 MQTT ile Illetilen Akım Değerleri

Ölçüm sırasında meydana gelen $\% 1,5$ hata payının analog ölçümlerde meydana gelen gürültüden kaynaklandığı kanısına varılmıştır. Gürültünün düşürülmesi amacıyla ağ geçidinin analog girişi (ADC) ile akım trafosunun çıkışına filtre devresi tasarlanmıştır. Ölçümler tekrar alındığında ise gürültü $\% 0,3$ hata payına indirgenmiştir (Şekil-13).

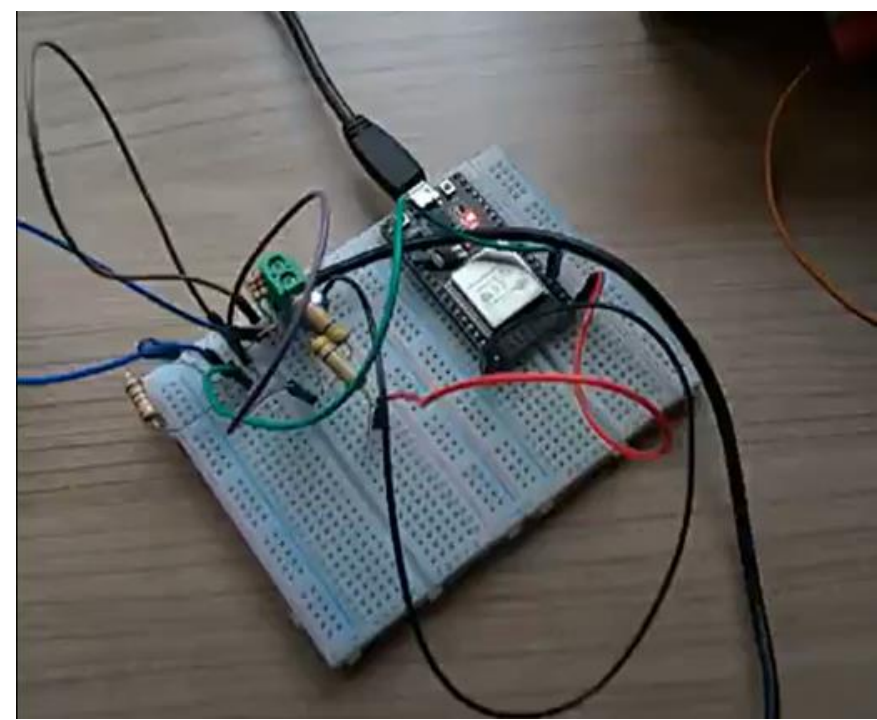

Şekil-13 ADC Filtre Devresi

Elektrik motoru test ortamında çeşitli arıza senaryolarına tabi tutularak toplamda 8433 adet veri toplanılmışıı (Şekil-14).



Şekil- 14 Elektrik Motoruna Ait Veriler

Elde edilen veriler üzerinden bir yapay zekâ modeli olan Uzun Kısa Süreli Bellek (LSTM) ile 4 katmanlı hücre oluşturulmuştur (Şekil-15). 


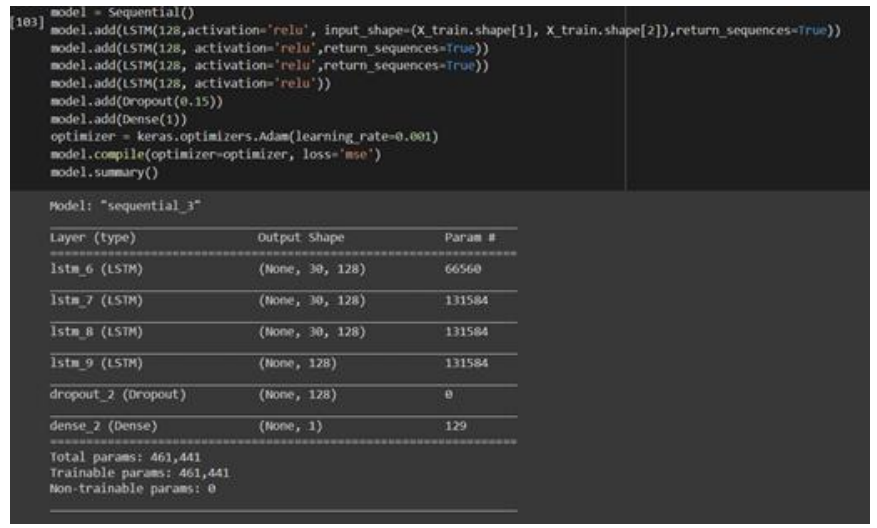

Şekil- 15 Uzun Kisa Süreli Bellek (LSTM)

Eğitim sonuçlarına göre saat 07:48:30 - 07:49:20 zaman dilimlerinde akım miktarlarında anormallik algılanmıştır. Motorun çalışma aralığ 1 yapay zekâ modeli ile 2.6 - 3.0 amper seviyeleri normal kabul edilmiş olup bu aralığın altında veya üstünde çıkan her değer için model anormallik uyarısı vermiştir (Şekil-16).

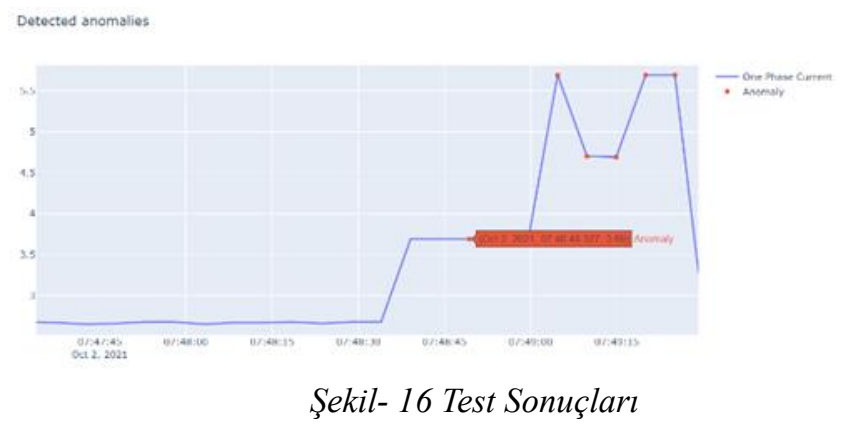

\section{Tartışma}

Akım sensörlerinden ağ geçidine giden kabloların üzeri elektromanyetik gürültülerden etkilenmemesi maksadıyla dış yalıtımlı kablo ile değiştirilmiştir. $\mathrm{Bu}$ yalıtımın sensör çıkış ucunda da devam edebilmesi için $3.5 \mathrm{~mm}$ jack konektör takılmıştır.

Elektrik motoru çeşitli zaman dilimlerinde değişik arıza senaryolarına tabi tutularak farklı türde veri grupları toplanmıştır. Elde edilen bu veriler ile yapay zekâ modeli bir ve birden fazla katmanlar ile eğitimler gerçekleştirilmiş̧tir. Bu eğitim sonuçları karşılaştırıldığında ortalama 8 bin veride modelin doygunluğa erişmesi (öğrenmenin tamamlanması) için en az 4 katmanlı bir model kullanılması gerektiği anlaşılmıştır.

Testleri tamamlanan modelin sahada da doğruluğunun kanıtlanması amacıyla endüstriyel bir bandın üzerinde bulunan üç fazlı bir elektrik motoruna entegre edilmiştir. Bir hafta boyunca motordan gelen veriler veri tabanına aktarılmıştır. Daha sonra bulut katmanında bu veriler ile yapay zekâ modeli kendini eğitmiştir. Eğitim sonucunda oluşturulan yapay zekâ modeli havadan güncelleme (OTA) üzerinden sınır bilişim katmanın aktarılmıştır. Burada üç fazlı elektrik motorundan gelen bilgiler doğrultusunda B fazında motorun normalden fazla akım çektiği saplanmıştır. Bakıma alınan motorun B fazında gerçekten bir arıza olduğu bakım ekibi tarafindan tescillenmiş̧tir.

\section{Sonuçlar}

"IoT Sistemlerde Sınır Bilişim Destekli Anomali Tespiti" projesi farklı sektörlere uyarlanmaya devam etmektedir. Çalışmalar halihazırda devam ettiğinden başarıyla tamamlanması neticesinde öngörülen sonuçlar şunlardır;

- Çeşitli sektörde farklı görevlerde çalışan araç, gereç ve ekipmanı Nesnelerin İnterneti (IoT) platforma dahil edecektir.

- Nesnelerin İnterneti platformunda çalışan her sistemin verimliliği denetlenebilecektir.

- $\mathrm{Bu}$ sistemlerin bakım maliyetleri düşürülecektir.

- Gereksiz ekipman yenilemelerinin önüne geçerek kaynaklardan tasarruf edilecektir.

- Parça tedarikleri planlanacaktır.

- Bakım periyotları gerekli olduğu anlarda yapılacaktır.

- Sistemlerde yaşanan arıza süreçleriyle ilgili sorunlara ışık tutarak bunların önlenmesine yardımcı olacaktır.

- Sistemin devamlı çalışmasını sağlayarak arıza kaynaklı gecikmelere engel olacaktır.

- Yüksek verimli sistemler tasarlamayı mümkün hale getirecektir.

- Veri karmaşasının önüne geçerek kıymetli veriler oluşturacaktır.

- Gerçek zamanlı sistemlerde buluta yüklenilen yoğun iş yükünü azaltacaktır.

\section{Teşekkür}

Proje süresince bana her konuda rehberlik eden saygıdeğer yüksek lisans hocam Dr. Öğr. Üyesi Mahmut DURGUN' a, verdiği destekler sebebiyle annem Semra KIŞLAKÇI ile babam Hikmet KIŞLAKÇI' ya çok teşekkür ederim.

\section{Kaynaklar}

[1] D. R. Dündar, İ. Sariçiçek, E. Çinar, and A. Yazici, "Kestirimci Bakımda Makine Öğrenmesi: Literatür Araştırması Machine Learning In Predictive Maintenance : Literature Research,” vol. 29, no. 2, pp. 256-276, 2021.

[2] I. Lopes et al., "Requirements specification of a computerized maintenance management system-a case study," Procedia Cirp, vol. 52, pp. 268-273, 2016.

[3] A. I. Vlasov, P. V Grigoriev, A. I. Krivoshein, V. A. Shakhnov, S. S. Filin, and V. S. Migalin, "Smart management of technologies: Predictive maintenance of industrial equipment using wireless sensor networks," Entrep. Sustain. Issues, vol. 6, no. 2, pp. 489-502, 2018.

[4] T. P. Carvalho, F. A. Soares, R. Vita, R. da P. Francisco, J. P. Basto, and S. G. S. Alcalá, "A systematic literature review of machine learning methods applied to predictive maintenance," Comput. Ind. Eng., vol. 137, p. 106024, 2019.

[5] Z. M. Çınar, A. Abdussalam Nuhu, Q. Zeeshan, O. Korhan, M. Asmael, and B. Safaei, "Machine learning in predictive maintenance towards sustainable smart manufacturing in industry 4.0," Sustainability, vol. 12, no. 19, p. 8211, 2020.

[6] A. Cachada et al., "Maintenance 4.0: Intelligent and 
predictive maintenance system architecture," in 2018 IEEE $23 \mathrm{rd}$ international conference on emerging technologies and factory automation (ETFA), 2018, vol. 1, pp. 139-146.

[7] U. Ozkaya, Ş. Öztürk, K. Tuna, L. Seyfi and B. Akdemir, "Faults Detection With Image Processing Methods In Textile Sector". in 1st International Symposium on Innovative Approaches in Scientific Studies, 2018.

[8] P. Maintenance and F. O. R. Industry, "Endüstri için kestirimci bakim," vol. 1, pp. 56-66, 2019.

[9] E. Sisinni, A. Saifullah, S. Han, U. Jennehag, and M. Gidlund, "Industrial internet of things: Challenges, opportunities, and directions," IEEE Trans. Ind. informatics, vol. 14, no. 11, pp. 4724-4734, 2018.

[10]H. Rashtian and S. Gopalakrishnan, "Using deep reinforcement learning to improve sensor selection in the internet of things," IEEE Access, vol. 8, pp. 95208-95222, 2020, doi: 10.1109/ACCESS.2020.2994600.

[11]B. N. Kars, "Edge Computing Security with an IoT device," vol. 1, no. June, pp. 14-17, 2021.

[12]D. Kong, D. Liu, L. Zhang, L. He, Q. Shi, and X. Ma, "Sensor anomaly detection in the industrial internet of things based on edge computing," Turkish J. Electr. Eng. Comput. Sci., vol. 28, no. 1, pp. 331-346, 2020, doi: 10.3906/elk-1906-55.

[13]“Akım trafosu nedir? Ne işe yarar? Nasıl çalışır? Nasıl seçilir?".

[14]"The Internet of Things with ESP32." .

[15]"Diğer W5500 Mini Ethernet Modül - 139,24 TL.".

[16]“Uzun / Kısa Süreli Bellek (Long / Short Term Memory) Veri Bilimcisi.".

[17]"How to Learn Long-Term Trends with LSTM | by Michael Berk | Aug, 2021 | Towards Data Science.”. 